\title{
Effects of conspecific odor on rats' position and behavior in an open field
}

\author{
P. A. RUSSELL and C. J. W. CHALKLY-MABER \\ University of Aberdeen, Old Aberdeen, $A B 92 U B$, Scotland
}

\begin{abstract}
When rats were tested in a novel open field, half of which had previously been occupied by a conspecific, they tended to enter the predecessor half first and subsequently spent more time in this half. There was proportionally more sniffing of the floor, sniffing of the air, and grooming in the predecessor half compared with the clean one, and proportionally less ambulating, rearing, and sniffing of the wall. Time spent in the predecessor half was unaffected by whether or not the predecessor had been tested under a relatively stressful condition (strong illumination), but rats tested after a "stressed" conspecific ambulated and reared less and showed more inactivity and thigmotaxis. Predecessor influence may be mediated by qualitative and/or quantitative differences in odor associated with urine traces, an influence that could affect results during routine successive open-field testing.
\end{abstract}

Laboratory studies of animal behavior frequently involve successive testing of subjects in the same apparatus. In view of the growing evidence that conspecific odors generated under various conditions can affect behavior (e.g., Bronson, 1974; Myktowycz, 1974) and the fact that procedures for removing odor are usually cursory or absent, the odor left by previous animals is an uncontrolled potential influence.

This study sought to examine the effect of predecessor odor on the behavior of rats in an open field. Since specialized external scent glands have not been identified in the rat, any odor effects in this species in this apparatus are probably associated with urine traces. During routine testing, feces are invariably removed after each rat but urine traces are unlikely to be completely eliminated except by thorough washing.

Although there are clear indications that rat and mouse conspecific odors can have attractant (Richards and Stevens, 1974, with rats; Whittier \& McReynolds, 1965, with mice) and repellant (Jones \& Nowell, 1974; Müller-Velten, 1966, both with mice) effects which influence an animal's position in the apparatus, few studies have investigated the effect of odors on the kinds of behavior conventionally measured in studies of emotional and exploratory behavior, e.g., ambulation, rearing, sniffing, freezing, and defecation. Stevens \& Köster (1972) found that male rats stopped moving more often and for longer when on a surface previously contacted by another male. Archer (1974) reported various behavioral differences between rats tested in an open field previously occupied by a same-sex conspecific and in a clean field, although the effects were sex and strain dependent.
The lack of detailed information on possible behavioral changes associated with conspecific odor is especially obvious in the case of effects associated with stressing the predecessor. Mice will avoid an area or airstream associated with a stressed conspecific, suggesting the existence of a "fear substance" or "fear odor" (Carr, Martorano, \& Krames, 1970; Müller-Velten, 1966; Rottman \& Snowdon, 1972), but the possibility that other aspects of behavior are affected has not been investigated systematically. Archer (1974) suggested that the increased defecation and flight distance to a bell in Sprague-Dawley male rats tested in an open field previously occupied by a same-sex conspecific might represent an increase in emotional indices stimulated by a fear odor (though females and other strains did not show the same effect).

Predecessor stress was therefore included as a factor here, together with the sex of the subject and sex of the predecessor to examine potential same and opposite sex effects which could occur in a typical study where males and females follow one another. Several aspects of spontaneous open-field behavior were recorded and the conspecific odors were localized in one half of the field to examine their effects upon the subjects' postion in the field.

\section{METHOD}

\footnotetext{
Subjects

Ninety-six male and 96 female hooded Lister rats, approximately 150-180 days old, were used. They had been housed from weaning in same-sex groups of two or three. Approximately 50 days prior to testing, they had served as subjects in a head-poke exploration study (apparatus described by Russell, 1977) which had afforded some incidental exposure to novel conspecific odors. The subgroups described below were fully matched with respect to differences in the previous experience of the subjects in this
} 
earlier study. Forty-eight males and 48 females served as subjects and the remainder as "predecessors" (each used once only). Subjects and predecessors were housed in separate (but identical) rooms and so had no contact during the experiment. The colony was illuminated from $0800 \mathrm{~h}$ to $2000 \mathrm{~h}$, and testing occurred about the middle of this period.

\section{Apparatus}

The open field was $85 \mathrm{~cm}$ square with $30-\mathrm{cm}$-high walls. The walls were flat black, while the floor consisted of a clear Perspex sheet over a white base divided by black lines into 16 squares of side $21.5 \mathrm{~cm}$. The floor was covered with a sheet of white absorbent paper, which was changed after each subject and through which the floor lines were visible. The field could be divided in half by inserting a $30-\mathrm{cm}$-high black dividing wall. The field was located in the center of the floor of a black cubic enclosure of side $1.5 \mathrm{~m}$, one wall of which was of black cloth permitting access to the field and having a $25-\mathrm{cm}$-square observation hole. The field could be illuminated by a bulb set $1.25 \mathrm{~m}$ above its floor; this was a $275-\mathrm{W}$ photoflood or a $40-\mathrm{W}$ red bulb, depending on the condition employed. Masking noise of approximately $50 \mathrm{~dB}$ at the center of the field came from an extractor fan.

\section{Procedure}

Immediately before each subject was tested, a predecessor was confined to one half of the field for $10 \mathrm{~min}$ under either a relatively stressful condition (referred to as "stress"), in which the field was illuminated by the photoflood, or a less stressful condition ("control"), in which the field was not illuminated. The rationale for the stress condition is that rats are averse to bright light, which increases defecation and reduces activity in a novel environment (pilot work and Williams, 1971). The predecessor was then removed, any feces taken out, the divider removed, and a subject placed in the field under the $40-\mathrm{W}$ red bulb. The interval between removal of the predecessor and placement of the subject was $4 \mathrm{~min}$; measurement showed that this interval was sufficient for the slight increase in air temperature just above the floor produced by the photoflood to have disappeared. Following a 10 -min test period, the subject was returned to its cage and the paper floor of the field discarded. The Perspex floor and the walls were then thoroughly washed with detergent solution and dried before clean paper was inserted for the next predecessor. Subjects were placed initially in the center of the field astride the midline separating predecessor and clean halves, and predecessors were placed in the center of their half, both facing away from the observer. The subjects were divided into eight groups each containing 12 rats, i.e., $M+$ SMP, M + CMP, M + SFP, M + CFP, F + SMP, F + CMP, $F+$ SFP, AND F + CFP, where $M=$ male, $F=$ female, $\mathrm{P}=$ predecessory, $\mathrm{S}=$ stressed, $\mathrm{C}=$ control, and $+=$ following. Several subjects were tested per day over several weeks in random order. Within each group, six predecessors were confined in the left half of the field and six in the right. During the test period, every $5 \mathrm{sec}$ a coded note was made of which square the subject occupied (where two or more squares were straddled, the one containing the larger area of the rat's body, excluding the tail, was recorded) and the behavior it was engaged in. Behavior was assessed using the following mutually exclusive and jointly exhaustive categories, similar to those of Russell (1973) except that the object of sniffing behavior was specified. Ambulating - walking or running (often accompanied by sniffing). Rearing-both forepaws off the floor and not grooming (also often accompanied by sniffing). Stationary sniffing the airsniffing indicated by whisker movement and nose twitching, with the nose not near the wall or floor and the rat otherwise inactive (i.e., not ambulating, rearing, etc.) Stationary sniffing the flooras sniffing the air except the nose touching or very close to the floor. Stationary sniffing the wall-as sniffing the floor except the nose touching or very close to the wall. Grooming-any selflicking, washing, or scratching. Inactive-standing, crouching, or lying, motionless except for occasional slight head movement and not sniffing. Miscellaneous-any other behavior, e.g., yawning, stretching, turning around. Defecation was scored as the number of fecal boluses left at the end of the test period. Interobserver reliabilities were assessed by correlating the scores of two practised observers recording simultaneously during pilot work: the correlations for each of the squares and for each of the behavioral categories were all significant at $<.01$ or better.

\section{RESULTS}

\section{First Entry into a Half}

Fifty-seven of the 96 rats entered the predecessor half first, an initial preference that approaches significance $\left[\chi^{2}(1)=3.37, p<.10>.05\right]$. This preference did not reach significance for any of the eight groups considered individually but rats having a male predecessor were significantly more likely to enter the predecessor half first than the clean one [32/48 rats, $\left.\chi^{2}(1)=5.33, \mathrm{p}<.05\right]$, though the same was not true of rats having a female predecessor $(25 / 48)$ and there was no significant difference in the numbers of rats from the male and female predecessor groups entering the predecessor half first. Neither predecessor test condition nor subject sex influenced first entry.

\section{Position in the Field}

An initial analysis of predecessor vs. clean halves showed that, overall, the rats spent more time in the predecessor half $[83 / 96$ rats were recorded as being more often in this half, $\chi^{2}(1)=51.04$, $\mathrm{p}<.001]$. As the scores for the two halves are not independent, a separate analysis of variance with repeated measures was carried out for each half, with predecessor test condition, predecessor sex, subject sex, and squares as factors. The squares factor had four levels corresponding to the four squares, A, B, C, and D, shown in Figure 1. Dividing a half across its midline produces quarters that are mirror images, and so the scores for squares $A^{\prime}$ and $A^{2}$, $\mathrm{B}^{\prime}$ and $\mathrm{B}^{2}$, etc., were combined.

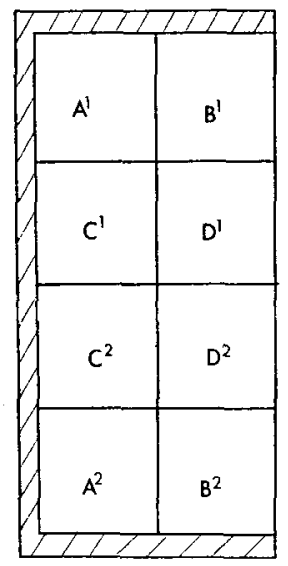

Figure 1. The eight squares comprising one half of the open field. Scores for $A^{\prime}$ and $A^{2}, B^{\prime}$ and $B^{2}$, etc., were combined. 
All groups preferred the predecessor half over the clean one to the same extent: neither the predecessor half nor the clean half analyses yielded effects due to predecessor test condition, predecessor sex, subject sex, or interactions. In both halves, however, the squares factor was significant $[F(3,264)=160.7$ and 66.02, $\mathrm{p}<.01$, for the predecessor and clean halves, respectively]. The mean percentages of the total observations scored for each square are shown in Table 1. Post hoc paired mean comparisons by Tukey's method (Ryan, 1959) revealed that within each half all square differences were significant at $<.01$ or better except for the $C / D$ comparison in the clean half. Most time was spent in the corner squares (A), followed by the squares with one adjacent wall ( $B$ and $C$ ), with least time in the inner squares (D), which is consistent with other reports of thigmotaxis (corner and wall hugging) in rats (e.g., Valle, 1970).

In the predecessor half only, squares interacted with predecessor test condition $[\mathrm{F}(3,264)=2.89$, $\mathrm{p}<.05]$ and with subject $\operatorname{sex}[\mathrm{F}(3,264)=4.03$, $\mathrm{p}<.011$. These effects are also shown in Table 1 . More time was spent in the corner squares when the predecessor had been stressed $(p<.01)$, with a corresponding decrease in time in the other squares. Females spent more time in the corner squares than did males $(p<.01)$. Thus, thigmotactic behavior was greatest in females and in subjects tested following a stressed animal. Corresponding, but nonsignificant, effects also occurred in the clean half.

\section{Behavior in the Field}

Total scores on each behavioral measure were computed for the predecessor and clean halves separately. Since more time was spent in the predecessor half, each behavioral score was expressed as a percentage of the total number of times that animal had been recorded in the particular half. The following analyses thus refer to the relative frequency score, not the absolute frequency. In each case, the analysis of variance had predecessor test condition, predecessor sex, and subject sex as between-subject factors and predecessor vs. clean half as a withinsubjects factor. Only significant effects are pre- sented. The miscellaneous behavior category was not analyzed owing to its low frequency.

Predecessor vs. clean halves: Sniffing of the floor, sniffing of the air, and grooming were all proportionally more frequent in the predecessor half than in the clean one $[F(1,88)=69.95,4.71$, and 8.16, $\mathrm{p}<.001,<.05$, and $<.01$, respectively]. Ambulation, rearing, and sniffing of the wall were proportionally less frequent in the predecessor half $[F(1,88)$ $=39.34,19.48$, and $21.79, \mathrm{p}<.001$ in each case] Predecessor test condition: Rats tested after a stressed predecessor showed less ambulation $[F(1,88)$ $=4.12, \mathrm{p}<.05]$, slightly less rearing $[\mathrm{F}(1,88=3.78$, $\mathrm{p}<.10]$, and more inactivity $[\mathrm{F}(1,88)=9.66, \mathrm{p}<$ $.01]$ compared with those following a control predecessor. Subject sex: Females ambulated, reared, sniffed the wall, and groomed more than males $[\mathrm{F}(1,88)=6.88,20.63,9.36$, and $4.95, \mathrm{p}<.02$, $<.001,<.01$, and .05 , respectively]. Males showed more sniffing of the floor, sniffing of the air, and inactivity $[\mathrm{F}(1,88)=32.97,6.84$, and $4.59, \mathrm{p}<$ $.001,<.02$, and $<.051$. Interactions: The only interaction occurred for sniffing of the air and involved predecessor test condition and subject sex $[F(1,88)$ $=5.75, \mathrm{p}<.02$ ], reflecting the fact that the tendency of males to sniff the air more than females was more marked when the predecessor had been stressed $(\bar{X}=20.9$ and 12.6) than when it had not $(\bar{X}=15.5$ and 15.2). Defecation: Only 27 of the 96 subjects defecated. The influence of each of the main between-subject factors was assessed by chisquare tests on the numbers defecating. Only subject sex was significant, with 21 males and 6 females defecating $\left[\chi^{2}(1)=10.10, \mathrm{p}<.01\right]$.

\section{DISCUSSION}

Rats clearly respond differently to an area of a novel environment which has recently contained a conspecific compared with a clean area, and it may be assumed that they are influenced by the conspecific's odor. They are slightly more likely to enter the predecessor area first and subsequently spend significantly more time in it. The latter finding confirms the reports of Richards and Stevens (1974, rats) and

Table 1

Mean Percentage of Observations in Each Field Square

\begin{tabular}{|c|c|c|c|c|c|c|c|c|c|c|}
\hline \multirow[b]{2}{*}{ Square } & \multicolumn{5}{|c|}{ Predecessor Half } & \multicolumn{5}{|c|}{ Clean Half } \\
\hline & A & $\mathrm{B}$ & $\mathrm{C}$ & $\mathrm{D}$ & Total & $\mathrm{A}$ & B & $\mathrm{C}$ & $\mathrm{D}$ & Total \\
\hline All Groups & 35.2 & 14.7 & 9.7 & 4.5 & 64.1 & 17.3 & 9.8 & 5.5 & 3.3 & 35.9 \\
\hline $\begin{array}{l}\text { Stressed Predecessor } \\
\text { Control Predecessor }\end{array}$ & $\begin{array}{l}37.7 \\
32.7\end{array}$ & $\begin{array}{l}13.1 \\
16.2\end{array}$ & $\begin{array}{r}9.2 \\
10.3\end{array}$ & $\begin{array}{l}3.4 \\
5.7\end{array}$ & $\begin{array}{l}63.4 \\
64.9\end{array}$ & $\begin{array}{l}18.5 \\
16.0\end{array}$ & $\begin{array}{r}9.6 \\
10.0\end{array}$ & $\begin{array}{l}5.7 \\
5.4\end{array}$ & $\begin{array}{l}2.8 \\
3.7\end{array}$ & $\begin{array}{l}36.6 \\
35.1\end{array}$ \\
\hline $\begin{array}{l}\text { Male Subject } \\
\text { Female Subject }\end{array}$ & $\begin{array}{l}31.7 \\
38.7 \\
\end{array}$ & $\begin{array}{l}15.8 \\
13.5 \\
\end{array}$ & $\begin{array}{r}10.1 \\
9.3 \\
\end{array}$ & $\begin{array}{l}5.1 \\
3.9 \\
\end{array}$ & $\begin{array}{l}62.7 \\
65.4 \\
\end{array}$ & $\begin{array}{l}16.4 \\
18.2 \\
\end{array}$ & $\begin{array}{r}11.3 \\
8.3 \\
\end{array}$ & $\begin{array}{l}6.4 \\
4.7 \\
\end{array}$ & $\begin{array}{l}3.2 \\
3.4 \\
\end{array}$ & $\begin{array}{l}37.3 \\
34.6\end{array}$ \\
\hline
\end{tabular}


Whittier and McReynolds (1965, mice). In addition, there are differences in the rats' behavior in the two areas. Taking behavior in the clean area as a baseline, the proportion of time in the predecessor area devoted to stationary sniffing of the floor and the air increases, which presumably reflects sampling of the conspecific odor. Ambulating, rearing, and sniffing the walls are proportionally reduced in the predecessor area, which may indicate that odor sampling in a predecessor area occurs at the expense of these behaviors, implying that they would normally occupy more time in an environment free of conspecific odor. Alternatively, the greater proportion of time spent ambulating, rearing, and sniffing the walls in the clean area may indicate an increase over the normal level of these behaviors brought about by the presence of odor in the predecessor area. Such an increase would occur if these behaviors reflected the search for conspecific odor in the clean area. In this case, behavior in both areas is influenced by the presence of odor in the predecessor area. The proportion of time spent inactive is not different in the two areas. The fact that grooming occupies proportionally less time in the clean area could mean either that odor searching in this area detracts from normal grooming or that grooming in the predecessor area is facilitated by the presence of conspecific odor.

The subject's behavior is also affected by the degree of stress to which the predecessor has been subjected. Although this factor does not affect the amount of time the subject spends in the predecessor area, it does influence both its behavior and its position within and outside the area. Rats tested after a relatively stressed predecessor show more thigmotactic behavior (hugging the corners and the walls) in the predecessor area and a similar, but less marked, increase in this behavior in the clean area. They also spend less time ambulating and rearing and more time inactive in both areas. To the extent that high levels of thigmotaxis and inactivity and low levels of ambulation and rearing have been regarded as indices of emotional or fearful behavior (see Archer, 1973, and Walsh \& Cummins, 1976, for evidence and reservations), rats tested after a stressed conspecific appear to be more emotional than those tested after one which has been less stressed. The effect thus appears broadly similar to that reported for Sprague-Dawley males tested after a conspecific by Archer (1974) and to the lowering of activity in rats following a stressed conspecific obtained by Stevens and Köster (1972). It is noteworthy, though, that defecation, widely regarded as an index of emotionality, is here unaffected (though overall defecation was relatively uncommon). The increased thigmotaxis of rats following a stressed predecessor might be explainable in terms of their investigating the areas of greatest odor deposition if, as might be predicted, the stressed rats themselves show increased thigmotaxis, though this is rendered less likely by the existence of the similar (though smaller) effect in the clean area. In addition, conspecific stress reduced ambulation and rearing and increased inactivity in the clean half as well as the predecessor one, and so these effects at least are not dependent on the subject being in direct contact with the odor area. The decreased ambulation and rearing following a stressed predecessor are not accompanied by the increased floor and air sniffing which would be expected if these decreases were simply the incidental consequence of increased sampling of the odor of stressed rats compared with less stressed ones. The results thus argue strongly that the subjects' emotional behavior is increased by a "stress cue" left by stressed predecessors.

The precise nature of this cue, however, remains to be clarified. One possibility already noted is that of a specific fear or stress odor. This could entail either a qualitative or a quantitative difference in the odor left by high- and low-stress rats. Alternatively, the effect could be mediated by a simple quantitative difference in the amount of urine deposited by the two groups. Measurement and/or control of the quantity and distribution of urine is necessary to check this point.

Regarding the attractant and aversive effects of conspecific odor, in the present case all conspecific odors proved attractive in terms of the time subjects spent in the predecessor area. Paradoxically, this was true even of the odor from a stressed conspecific which, though it appeared to increase emotionality, was not avoided. Existing reports of stress-odor avoidance involve mice (see introduction), and it may be that rats differ in this respect, although more data on the effects of rat stress odor is clearly required.

The lack of sex-related odor effects is also notable. In particular, there is no evidence that subjects are more attracted to, or behave differently in the presence of, the odor from opposite-sex predecessors. It is known that male rats prefer the odor of sexually receptive females over that of nonreceptive females and other males (Carr, Loeb, \& Dissinger, 1965), and, conceivably, different results would be obtained with female groups consisting entirely of sexually receptive animals. The importance of the present finding is the suggestion that sex is unlikely to exert little overall bias in routine testing where the females are not selected for receptivity and where only a small proportion will be in estrus. Effects could also be different where subjects have a simultaneous choice of sex odors rather than simply being exposed to one as here.

\section{REFERENCES}

Arche R, J. Tests for emotionality in rats and mice: A review. Animal Behaviour, 1973, 21, 205-235.

Arche R, J. Sex differences in the emotional behavior of three 
strains of laboratory rat. Animal Learning \& Behavior, 1974, 2, 43-48.

Bronson, F. H. Pheromonal influences on reproductive activities in rodents. In M. C. Birch (Ed.), Pheromones. London: NorthHolland, 1974.

Carr, W. J., Loeb, L. S., \& Dissinger, M. L. Responses of rats to sex odors. Journal of Comparative \& Physiological Psychology, 1965, 58, 370-377.

Carr, W. J., Martorano, R. D., \& Krames, L. Responses of mice to odors associated with stress. Journal of Comparative and Physiological Psychology, 1970, 71, 223-228.

Jones, R. B., \& NowELl, N. W. A comparison of the aversive and female attractant properties of urine from dominant and subordinate male mice. Animal Learning \& Behavior, 1974, 2, 141-144.

Müllek-Velten, H. Über den Angst-geruch bei der Hausmaus (Mus musculus L.). Zeitschrift für Vergleichende Physiologie, $1966,52,401-429$.

MYKTOWYCZ, $R$. Odor in the spacing behavior of mammals. In M. C. Birch (Ed.), Pheromones. London: North-Holland, 1974.

Richards, D. B., \& Stevens, D. A. Evidence for marking with urine by rats. Behavioral Biology, 1974, 12, 517-523.

Rottman, S. J., \& Snowdon, C. T. Demonstration and analysis of an alarm pheromone in mice. Journal of Comparative \& Physiological Psychology, 1972, 81, 483-490.
Russel., P. A. Sex differences in rats' stationary-cage activity measured by observation and automatic recording. Animal Learning \& Behavior, 1973, 1, 278-282.

Russell, P. A. Sex differences in rats' stationary exploration as a function of stimulus and environmental novelty. Animal Learning \& Behavior, 1977, 5, 297-302.

Ryan, T. A. Multiple comparisons in psychological research. Psychological Bulletin, 1959, 56, 26-47.

Stevens, D. A., \& Köster, E. P. Open-field responses of rats to odors from stressed and nonstressed predecessors. Behavioral Biology, 1972, 7, 519-525.

VALLE, F. P. Effects of strain, sex, and illumination on open field behavior of rats. American Journal of Psychology, 1970, 83, 103-111.

Walsh, R. N., \& Cummins, R. A. The open field test: A critical review. Psychological Bulletin, 1976, 83, 482-504.

Whittier, J. L., \& McReynol,ds, P. Persisting odors as a biasing factor in open field research with mice. Canadian Journal of Psychology, 1965, 19, 224-230.

Williams, D. I. Maze exploration in the rat under different levels of illumination. Animal Behaviour, 1971, 19, 361-363.

(Received for publication September 8, 1978; revision accepted December $11,1978$. 